\title{
Flexible Riser Monitoring Using Hybrid Magnetic/Optical Strain Gage Techniques through RLS Adaptive Filtering
}

\author{
Daniel Pipa, Sérgio Morikawa, Gustavo Pires, Claudio Camerini, and João Márcio Santos
}

Materials, Equipments and Corrosion Department (TMEC), Petrobras' Research and Development Center (CENPES), Av. Horácio Macedo, 950. Cidade Universitária, 21941-915 Rio de Janeiro, RJ, Brazil

Correspondence should be addressed to Daniel Pipa, danielpipa@gmail.com

Received 30 November 2009; Revised 5 April 2010; Accepted 7 May 2010

Academic Editor: João Manuel R. S. Tavares

Copyright ( $\odot 2010$ Daniel Pipa et al. This is an open access article distributed under the Creative Commons Attribution License, which permits unrestricted use, distribution, and reproduction in any medium, provided the original work is properly cited.

\begin{abstract}
Flexible riser is a class of flexible pipes which is used to connect subsea pipelines to floating offshore installations, such as FPSOs (floating production/storage/off-loading unit) and SS (semisubmersible) platforms, in oil and gas production. Flexible risers are multilayered pipes typically comprising an inner flexible metal carcass surrounded by polymer layers and spiral wound steel ligaments, also referred to as armor wires. Since these armor wires are made of steel, their magnetic properties are sensitive to the stress they are subjected to. By measuring their magnetic properties in a nonintrusive manner, it is possible to compare the stress in the armor wires, thus allowing the identification of damaged ones. However, one encounters several sources of noise when measuring electromagnetic properties contactlessly, such as movement between specimen and probe, and magnetic noise. This paper describes the development of a new technique for automatic monitoring of armor layers of flexible risers. The proposed approach aims to minimize these current uncertainties by combining electromagnetic measurements with optical strain gage data through a recursive least squares (RLSs) adaptive filter.
\end{abstract}

\section{Introduction}

Flexible risers are an important component of offshore production systems of oil and gas. They are used to link subsea pipelines to floating installations, such as FPSOs (floating production/storage/off-loading unit). Flexible risers have been one of the preferred deepwater riser solutions in many regions of the world due to their good dynamic behavior and reliability [1].

Petrobras is a Brazilian multinational petroleum company whose businesses include oil and gas exploration, production, transportation, refining, and distribution. Since most Brazilian oil reserves are located offshore and often under deepwater, Petrobras oil production is highly dependent on platforms and offshore equipments such as flexible risers. Integrity management of flexible risers is essential to ensure the safe operation of a production unit.

The main failure mode of flexible risers, when operating in deep waters, occurs at the riser's top section close to end fitting due to fatigue in tensile armor wires. It is known, however, that riser failure only happens after the rupture of a significant number of wires. Therefore, the structural integrity of a riser-end fitting connection may be assessed through the monitoring of wire rupture. Close to the end fitting, wires are subjected to tensile stress at $30 \%$ to $50 \%$ of yield point. Considering that rupture reduces stress to zero, the structural integrity of end fitting connection may be also assessed through monitoring tensile armor wire stress [2].

By identifying an unstressed wire among stressed ones, it is possible to infer that the remnant wires are subjected to higher loads than their operational design. This implies that riser integrity is uncertain and insecure. MAPS-FR (MAPS is a registered trade mark of MAPS Technology Ltd.) is an equipment capable of magnetically comparing the stress in the wires through the polymer layers, thus indicating broken wires and assessing riser integrity.

However, one encounters several sources of noise when measuring electromagnetic properties contactlessly, such as movement between specimen and probe, and magnetic noise. This paper describes the development of a new technique for automatic monitoring of armor layers of flexible risers. The proposed approach aims to minimize 
these current uncertainties by combining electromagnetic measurements with optical strain gage data through a recursive least squares (RLSs) adaptive filtering technique.

This paper is organized as follows. Section 2 introduces the flexible riser and comments its main failure modes. Section 3 presents the proposed method as well as each of its components. Finally, Section 4 presents the results obtained in a laboratory trial, which attests the potential of the method. A conclusion is drawn in Section 5. "Flexible pipe" is a general term and denotes a type of pipe, whereas "flexible riser" designates the vertical segment of a pipe which is usually connected to an offshore production unit.

This article deals with signal processing algorithms, rather than physical phenomena underlying the correspondence between mechanical load in ferromagnetic materials and their electromagnetic properties. The idea is to show that this relation does not need be fully determined and understood if one uses a global load reference. Additionally, if there exists an unknown or unstable gap between probe and sample, this relation can be such complex that a nonreferenced measurement of stress can be difficult. On the other hand, some global load estimate can enhance the results.

\section{Flexible Risers}

Flexible risers are flexible pipes which are generally used to link subsea pipelines to floating offshore installations, such as FPSOs (floating production/storage/off-loading unit). In deep water oil and gas exploration flexible risers are used for oil and gas production, water and gas injection, and oil well control and monitoring [3]. Flexible risers are also used for oil and gas exportation to the shore or to a storage unit, such as FSOs (floating storage/off-loading unit).

A flexible pipe is made up of several different layers. The main components are leakproof thermoplastic barriers and corrosion-resistant steel wires. The helically wound steel wires give the structure its high-pressure resistance and excellent bending characteristics, thus providing flexibility and superior dynamic behavior. This modular construction, where the layers are independent but designed to interact with one another, means that each layer can be made fitfor-purpose and independently adjusted to best meet a specific field development requirement [4]. Figure 1 shows an example of flexible riser and Table 1 summarizes the function of each layer.

This paper focuses on the integrity monitoring of the outer layer of tensile armor, which supports axial load and the riser weight. Its integrity is important to maintain a reliable connection between riser and floating unit (i.e., FPSO or platform).

2.1. Riser Failure Modes. Failure modes denote possible processes which cause the failure of a flexible pipe. In practice, a failure constitutes a loss of ability to transport product safely and effectively. This may be catastrophic (the pipe ruptures or breaks) or may constitute a minor, uncontrolled loss of pipe integrity or pipe blockage [5].
TABLE 1: Layers' functions.

\begin{tabular}{ll}
\hline Layer & Function \\
\hline $\begin{array}{l}\text { Carcass } \\
\text { Internal } \\
\text { pressure sheath } \\
\text { Interlocked } \\
\text { pressure armor }\end{array}$ & Prevent collapse \\
$\begin{array}{l}\text { Back-up } \\
\text { pressure armor }\end{array}$ & Hoop stress resistance \\
Antiwear layer & Hoop stress resistance \\
$\begin{array}{l}\text { Inner layer of } \\
\text { tensile armor }\end{array}$ & $\begin{array}{l}\text { Crosswound armor wires used for tensile } \\
\text { Antiwear layer }\end{array}$ \\
$\begin{array}{l}\text { Outer layer of } \\
\text { tensile armor }\end{array}$ & $\begin{array}{l}\text { Reduce friction between layers } \\
\text { Crosswound armor wires used for tensile }\end{array}$ \\
Outer sheath & stress resistance balanced with inner layer \\
\hline
\end{tabular}

TABLE 2: Main failure modes of flexible pipes.

\begin{tabular}{|c|c|c|}
\hline No. & Failure mode & Description \\
\hline 1 & Collapse & $\begin{array}{l}\text { Collapse of carcass and/or pressure armor } \\
\text { due to excessive tension, excessive } \\
\text { external pressure or installation overloads }\end{array}$ \\
\hline 2 & Burst & $\begin{array}{l}\text { Rupture of tensile or pressure armors due } \\
\text { to excess internal pressure }\end{array}$ \\
\hline 3 & Tensile failure & $\begin{array}{l}\text { Rupture of tensile armors due to excess } \\
\text { tension }\end{array}$ \\
\hline 4 & $\begin{array}{l}\text { Compressive } \\
\text { failure }\end{array}$ & Birdcaging of tensile armor wires \\
\hline 5 & Overbending & $\begin{array}{l}\text { Rupture or crack of external or internal } \\
\text { sheaths }\end{array}$ \\
\hline 6 & $\begin{array}{l}\text { Torsional } \\
\text { failure }\end{array}$ & Failure of tensile armor wires \\
\hline 7 & $\begin{array}{l}\text { Fatigue } \\
\text { failure }\end{array}$ & Tensile armor wire fatigue \\
\hline 8 & Erosion & Of internal carcass \\
\hline 9 & Corrosion & $\begin{array}{l}\text { Of internal carcass or tensile/pressure } \\
\text { armor exposed to seawater or diffused } \\
\text { product }\end{array}$ \\
\hline
\end{tabular}

Table 2 describes the main failure modes of flexible pipes. The inspection and monitoring techniques suggested to detect and/or predict each failure mode are described in Section 2.2.

Periodic inspections have detected a considerable incidence of damage in the top section of risers (i.e., endfitting, Figure 2), which may affect their structural integrity and eventually induce different failure mechanisms. These include mostly external sheath damage, corrosion, and/or fatigue-induced damage to the tensile armors and torsional instability. These flaws are generally originated during installation or, more frequently, during operation due to contact with another riser or the platform structure $[2,6]$. Figure 3 shows an example of a failure where rupture of tensile wires occurred inside the end-fitting. 


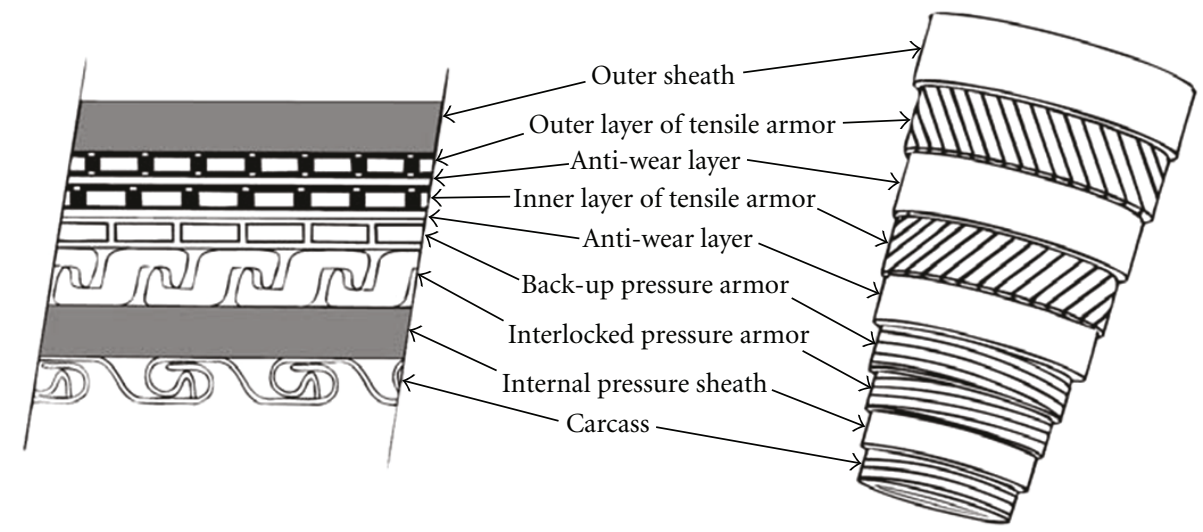

FIgURE 1: Unbonded flexible pipe.

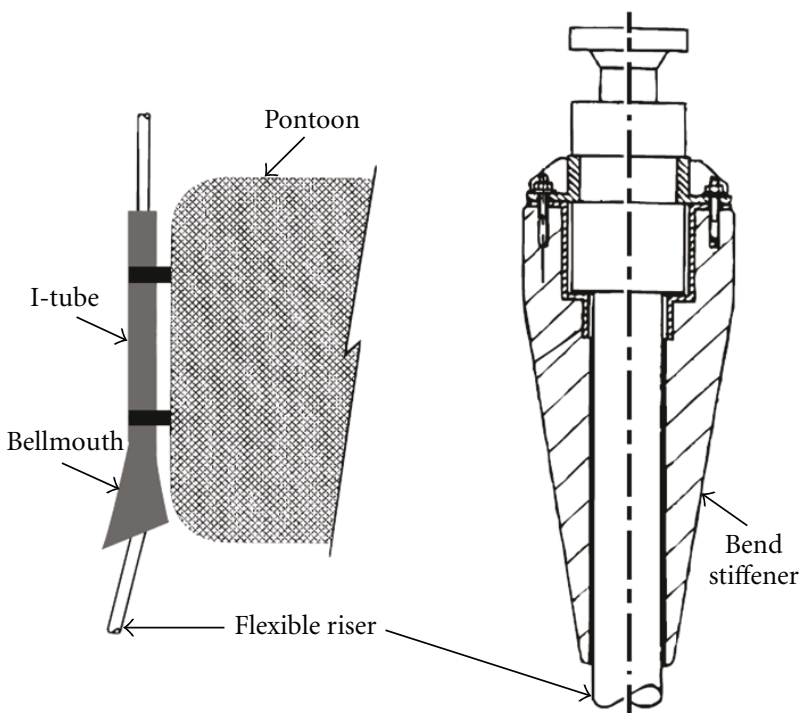

FIGURE 2: End-fitting.

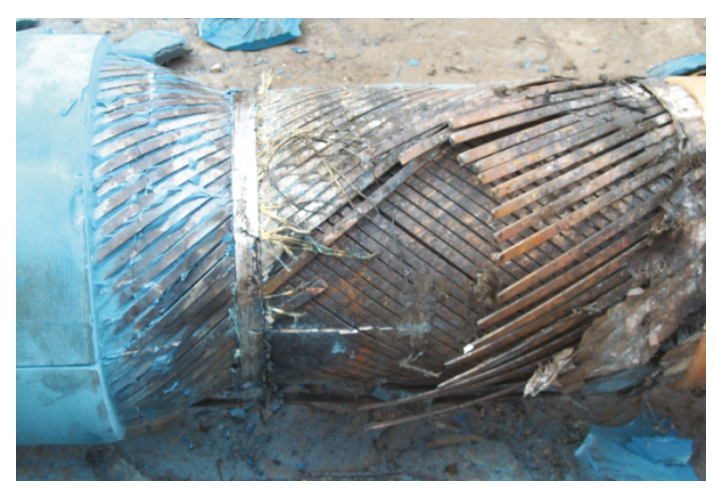

FIGURE 3: End-fitting failure example.

2.2. Flexible Riser Inspection and Monitoring. The Recommended Practice for Flexible Pipe [7], also known as API $17 \mathrm{~B}$, from the American Petroleum Institute, recommends some inspection and monitoring methods for in-service flexible pipes. Table 3 lists the monitoring methods as well

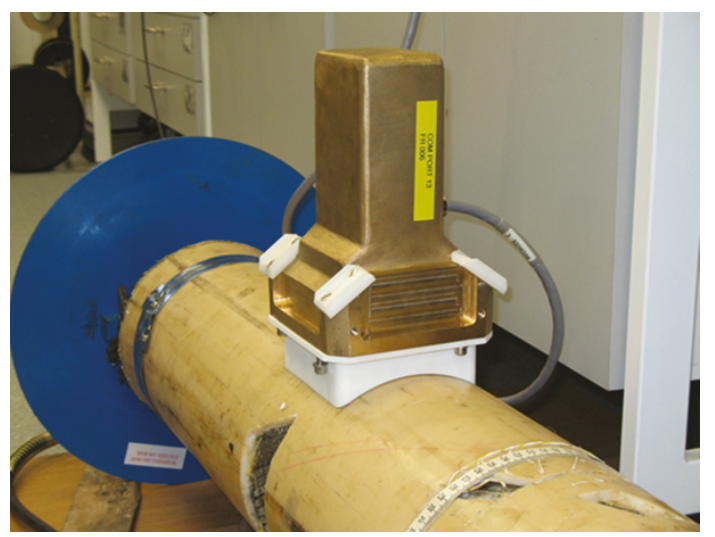

FIgURE 4: MAPS-FR probe.

as the failure modes that are covered by each method. Visual inspection and periodic pressure testing have been, to date, the most common forms of in-service monitoring used for the demonstration of continued fitness for purpose.

Several methods for managing the integrity of flexible pipes have been proposed in literature depending on the failure mode aimed [8-18]. As this work focuses on the detection of damage to tensile armor wires, the following survey of state-of-the-art methods will concentrate on techniques which directly or indirectly estimate the number of broken wires in armor layers.

Automated visual inspection has been employed by Petrobras as torsion monitoring. The method focuses on small angle deformation detection and on online data acquisition, in order to provide immediate identification for nonconformities. It consists of attaching a target on the riser and observing its behavior through a video camera, installed above the end fitting. The rupture of wires in the inner or outer layer can lead the riser to an unbalanced condition, thus generating torsion $[2,19]$. However, if the number of broken wires is not significant, torsion might not occur and broken wires might not be detected.

Acoustic emission has been applied to detect the instant of rupture of armor wires. An acoustic emission scheme 


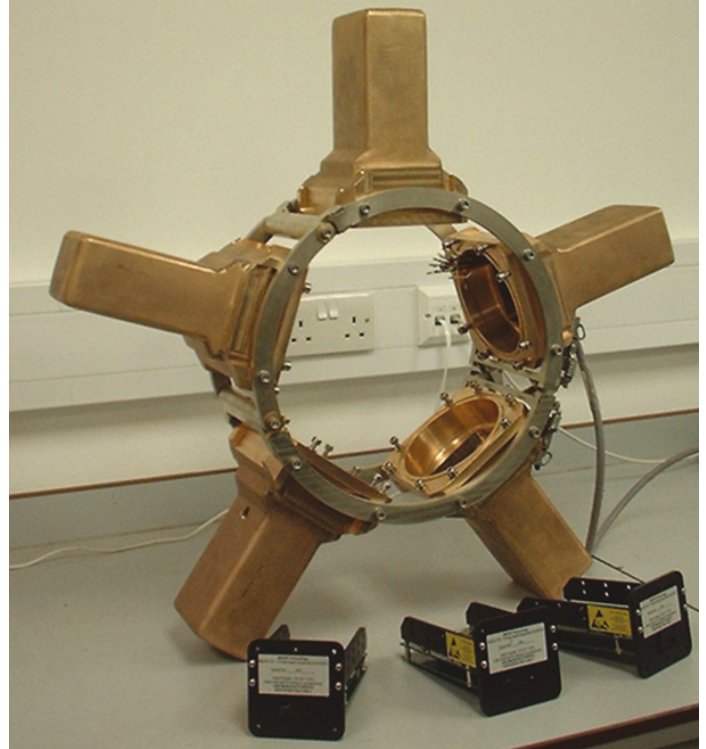

Figure 5: MAPS-FR ring.

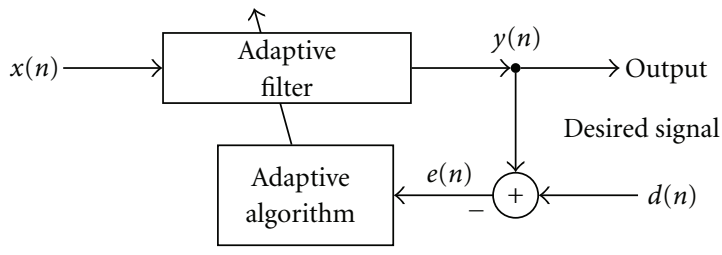

FIGURE 6: General adaptive filter configuration.

was developed in [20] based on laboratory tests and field experience. The idea is that when a tensile armor wire rupture takes place, a strong sound signal is generated. This great amplitude and energy sound wave can be distinguished, in relation to environmental noise, making acoustic emission a potential wire rupture detection technique. In [20], a procedure was designed to filter relevant acoustic events from spurious noisy emissions. The filtering scheme was applied to real data from a riser installed in the field. The riser was monitored for 11 months and then a dissection was performed. As no failure was found during the dissection, the filter parameters were adjusted to match the observed results. A drawback of this method is the need of continuous monitoring; that is, the rupture is not detected if the system is momentarily off. Also, other acoustic noises from the platform can cause false indications.

Fiber-optics Bragg grating (FBG) sensors technology has also been used to monitor flexible riser. In [21] two methodologies to monitor strain in flexible risers are developed. In the first approach, permanent FBG strain gages were installed on all wires of the armor layer. This approach allows identification of abrupt changes in the strain states of the wires, which may provide instantaneously detection of failure in one or more wires. The problem is that this method requires that the outer sheath be partially removed to access the wires. This is not always permitted in in-service risers.

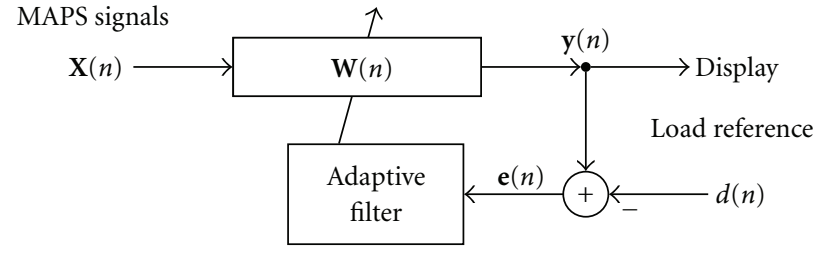

Figure 7: Hybrid adaptive filter.

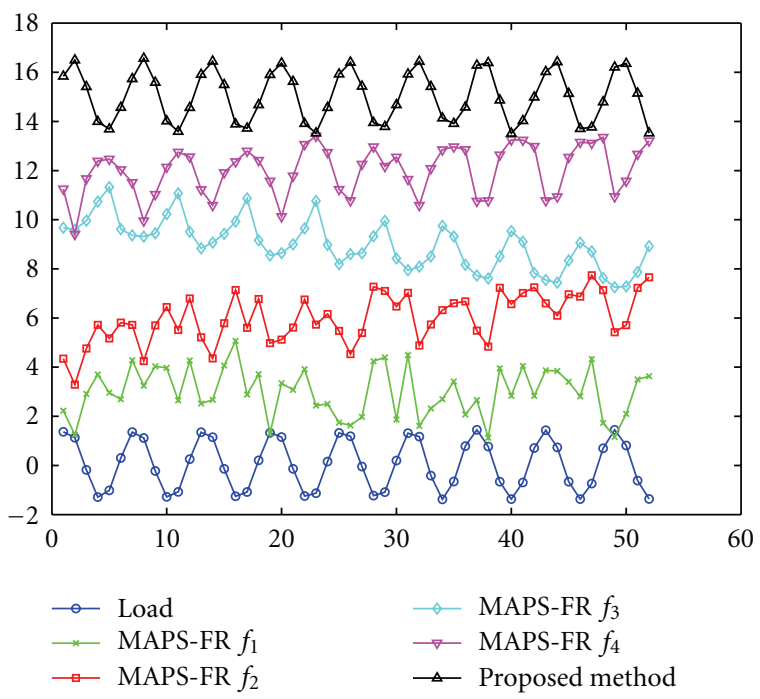

FIgure 8: Pure MAPS-FR signals aims to estimate the riser load. However, better results are achieved when the four signals are combined by the proposed method.

In the second methodology, a thin steel collar instrumented with FBG strain gages was placed around the riser outer layer, measuring circumferential strains and changes in its diameter. Wire failures can be detected as they can cause variation in the external diameter of the polymeric jacket covering the riser. The disadvantage of this technique is that the number of broken wires needed to cause a detectable variation in the external diameter can be significant.

Another scheme using FBG strain gages was proposed in [1]. It is based on a retrofit clamp that monitors axial elongation and torsion of a flexible riser. The clamp is instrumented with FBG strain gages. As the previously presented methods, it suffers from sensibility. That is, one single broken wire is unlikely to be detected as its effects on external geometry are minimal.

In [22] a technology that integrates FBG sensors along grooves in the tensile wires during manufacturing of the pipe is described. Thus, strain and temperature can be monitored along several meters of the wires and ruptures are easily detected. Although new flexible pipes can be manufactured with this feature, the technology cannot be applied to existing pipes.

The electromagnetic tool MAPS-FR, on which the proposed method is based, is described in [3]. This equipment can estimate the stress on armor wires in a noninvasive manner. Additionally, it is sensitive to a single broken wire 


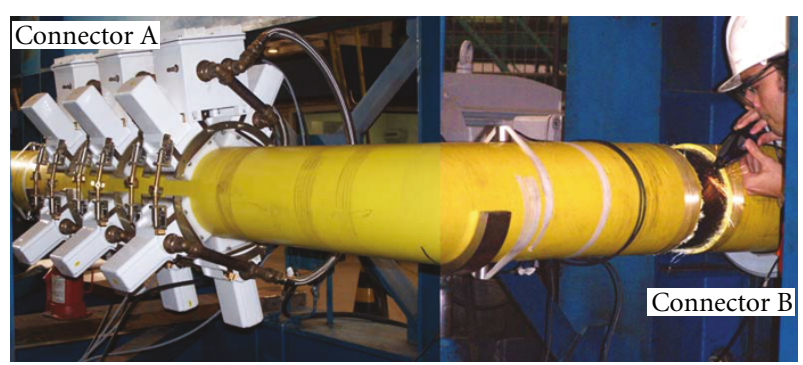

Figure 9: Trial.

TABLE 3: Flexible riser inspection and monitoring techniques suggested by API 17B and the failure modes (FM) covered by each method.

\begin{tabular}{|c|c|c|}
\hline $\begin{array}{l}\text { Monitoring } \\
\text { method }\end{array}$ & Description & $\begin{array}{c}\text { FM } \\
\text { covered }\end{array}$ \\
\hline $\begin{array}{l}\text { Visual } \\
\text { inspection } \\
\text { (internal and } \\
\text { external) }\end{array}$ & $\begin{array}{l}\text { Assessment of leakage or visible } \\
\text { deformation or damage to pipe or } \\
\text { outer sheath }\end{array}$ & $\begin{array}{l}1,4,5 \\
6,8,9\end{array}$ \\
\hline Pressure test & $\begin{array}{l}\text { Pressure applied to pipe and decay } \\
\text { measured as a function of time. } \\
\text { Leakages or anomalies identified }\end{array}$ & $1,2,5$ \\
\hline $\begin{array}{l}\text { Destructive } \\
\text { analysis of } \\
\text { removed } \\
\text { samples }\end{array}$ & $\begin{array}{l}\text { Prediction of the state of aging or } \\
\text { degradation }\end{array}$ & 8,9 \\
\hline $\begin{array}{l}\text { Load, } \\
\text { deformation } \\
\text { and } \\
\text { environment } \\
\text { monitoring }\end{array}$ & $\begin{array}{l}\text { Measured parameters include wind, } \\
\text { wave or current environment, vessel } \\
\text { motions, product temperature, } \\
\text { pressure and composition, and } \\
\text { structural (or flexible pipe) loads and } \\
\text { deformations }\end{array}$ & 7 \\
\hline $\begin{array}{l}\text { Nondestru- } \\
\text { ctive testing } \\
\text { of pipes in } \\
\text { service }\end{array}$ & $\begin{array}{l}\text { Radiography to establish the condition } \\
\text { of steel tensile armor and pressure } \\
\text { armor layers in service }\end{array}$ & $\begin{array}{c}2,3,4 \\
6,7\end{array}$ \\
\hline $\begin{array}{l}\text { Gaging } \\
\text { operations }\end{array}$ & $\begin{array}{l}\text { Gaging pigs to check for damage to the } \\
\text { internal pipe profile }\end{array}$ & $1,8,9$ \\
\hline Spool Piece & $\begin{array}{l}\text { To predict the state of aging or } \\
\text { degradation of the internal pressure } \\
\text { sheath }\end{array}$ & 8,9 \\
\hline Test pipe & $\begin{array}{l}\text { Use of a flexible test pipe in series or in } \\
\text { parallel with the flow which is } \\
\text { periodically removed for destructive or } \\
\text { nondestructive testing }\end{array}$ & 8,9 \\
\hline $\begin{array}{l}\text { Annulus } \\
\text { Monitoring }\end{array}$ & $\begin{array}{l}\text { Measurement of annulus fluid ( } \mathrm{pH}, \\
\text { chemical composition, volume). } \\
\text { Prediction of degradation of the steel } \\
\text { pressure armor or tensile armor layers } \\
\text { or the aged condition of the internal } \\
\text { pressure sheath or susceptibility of } \\
\text { annulus environment to such } \\
\text { degradation }\end{array}$ & 7,9 \\
\hline
\end{tabular}

since it does not depend on geometrical deformations in the external sheath. Section 3.1 is devoted to describe MAPS-FR.
Basically, most techniques that directly estimate the number of broken wires are intrusive, whereas nonintrusive techniques are not precise. It will be shown that the proposed methodology, on the other hand, combines both advantages detecting a single wire break in a nonintrusive manner. Moreover, the proposed method produces graphical representation of stress distribution on wires which can be effectively used for break detection.

\section{Proposed Method}

This section describes the proposed method. In Section 3.1 the electromagnetic equipment used to measure internal tensile stress in the wires is briefly presented. The RLS filter technique is deduced in Section 3.2. Finally, the hybrid approach, which combines MAPS-FR signals with optical strain gage data through RLS filtering, is presented in Section 3.3.

3.1. MAPS-FR: Stress Measurement Technology. The tool used as nonintrusive stress gage for tensile armors is MAPSFR. This equipment was developed by MAPS Technology in partnership with Petrobras. At the end of development process, Petrobras acquired the tool and has been developing its own signal processing algorithms, which are the main objective of this document. In the next lines, a brief presentation of MAPS-FR [23] tool is made. For a more complete description of MAPS-FR see [3].

In service the axial armor wires are subjected to tensile stress. In a failed wire, however, the applied tensile stress will be zero at the point of failure and will increase over some distance along the ligament from the break. The length over which the stress is increased depends on the amount of frictional load transfer to adjacent ligaments. If the length over which the stress reduction occurs is sufficiently long and the stress in the armor layer wires can be monitored, this would offer a method for detecting armor failure remotely from the actual failure location [3].

Most stress measurement techniques are not appropriate to monitor riser armor layers. Some, such as hole drilling, are clearly not satisfactory as they are not nondestructive and require access to the armor wires. Others, including neutron diffraction, and X-ray diffraction, are not suited to installed operation or, like ultrasonic methods, also need to be directly coupled to the material being measured [3].

Magnetic methods, on the other hand, do have the necessary attributes for an appropriate technology as intimate contact with the material being measured is not necessary $[24,25]$. Stress measurement is possible as it is known that the magnetic properties of ferromagnetic materials are sensitive to internal stress. However, there are important issues to overcome as it is also known that mechanical hardness, grain size, texture, and other material properties also affect magnetic parameters. MAPS [23] stress measurement technology has been adapted to perform stress measurement in flexible pipes. This technique involves a number of low-frequency electromagnetic measurements, 


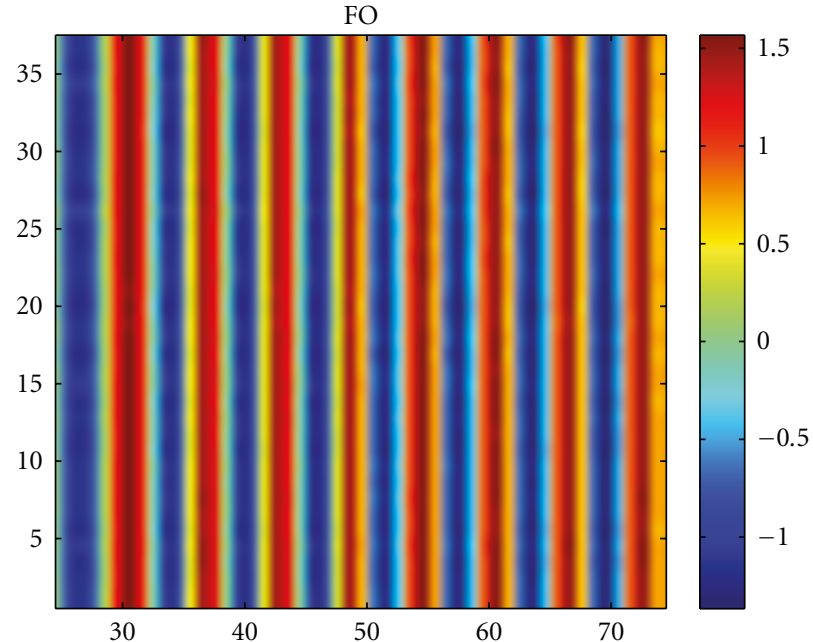

(a)

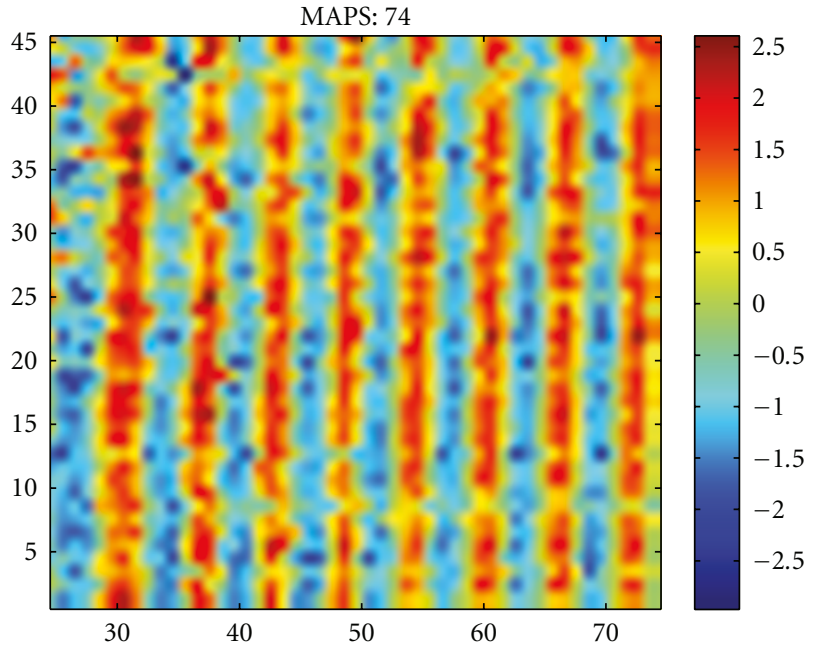

(b)

FIgURe 10: Normal cyclic loading.

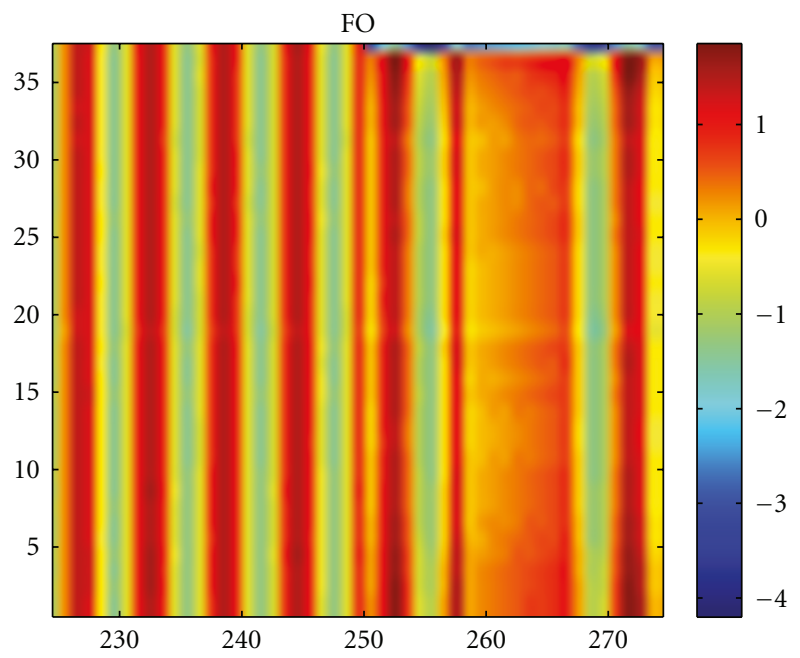

(a)

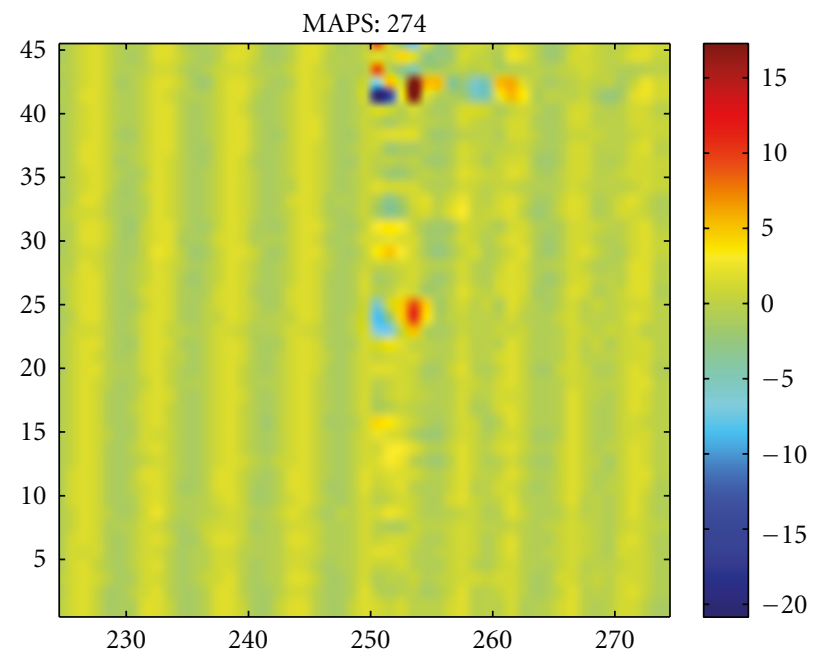

(b)

FIgURE 11: Wire 37 break.

some of which monitor material variations, whilst others are mainly stress sensitive [3].

3.1.1. MAPS-FR Tool Description. The basic component of the current MAPS-FR equipment is the so-called probe, shown in Figure 4. Each probe contains an excitation coil, which generates the electromagnetic field that propagates through riser's wires, and three sensing coils, which read the response of a wire or group of wire to the excitation field. As previously mentioned, the value read by sensing coils depends on the stress that the wires are subjected to.

Five probes are grouped together to form a ring, as shown in Figure 5. This assembly can now be mounted and fixed around the outer layer of the riser. As each probe has three sensing coils, a ring has fifteen sensing coils. The complete MAPS-FR equipment is composed by three rings, comprehending 45 sensing coils. Hence, the current MAPSFR set permits monitoring of approximately 45 wires on the external armor layer, although this can be altered to suit requirements.

3.1.2. MAPS-FR Data. The goal achieved by current MAPSFR technology is to compare tensile stress present in armor wires. Nonetheless, the interpretation of raw data requires an analysis by MAPS-FR experts. As a result, an indication of a possible wire rupture is signalized including its circumferential localization.

During the development of MAPS-FR system, Petrobras and MAPS Technology jointly performed several controlled laboratory tests. In these tests, specific wires were induced to failure by the introduction of notches on their surfaces. Blind tests were also performed, where only the Petrobras team was 


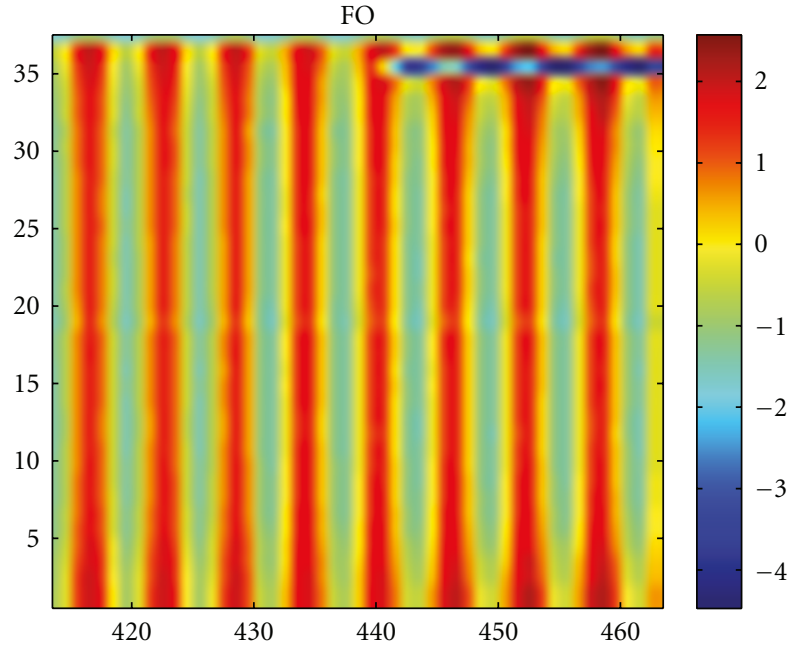

(a)

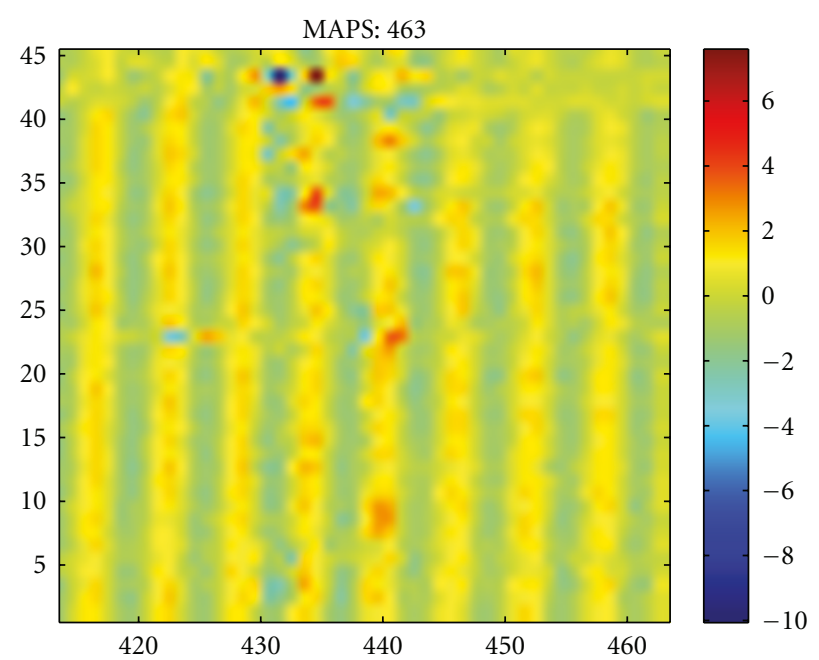

(b)

Figure 12: Wire 35 break.

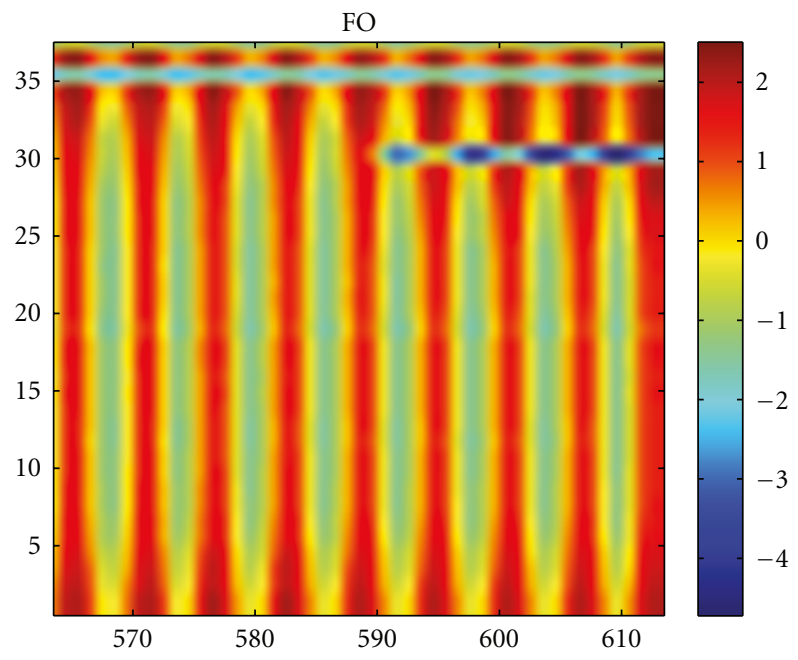

(a)

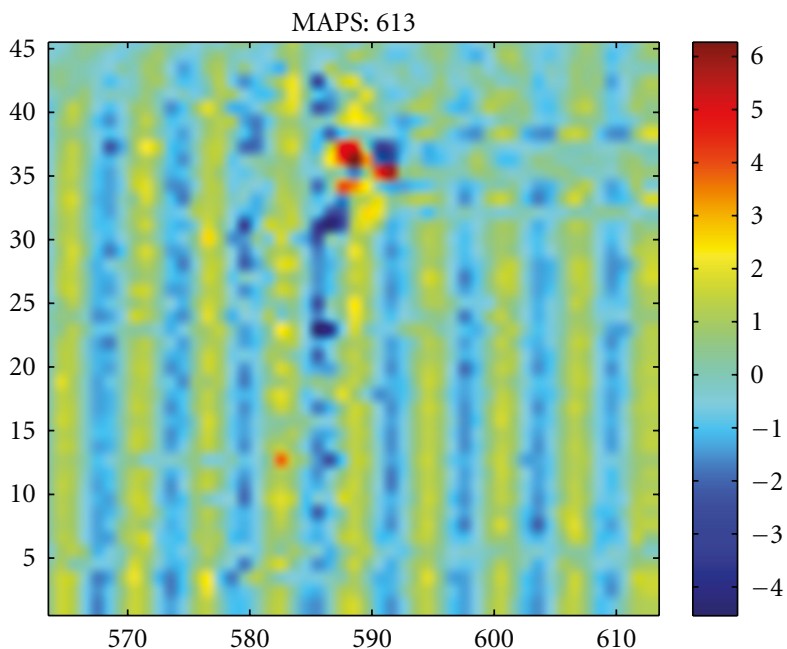

(b)

FIGURE 13: Wire 30 break.

acquainted with damage wires and the MAPS Technology team had to give indication of broken wires based only on MAPS-FR's signals. In the final blind test, MAPS-FR experts correctly indicated $100 \%$ of wire breaks with 1 false positive indication over 9 correct indications.

The raw MAPS-FR signals exhibit a slow time drift probably due to accommodations of riser's internal layers during a load variation. This drift must be carefully considered in order not to be misinterpreted as a wire break. Automatic break detection algorithms have to compensate these phenomena avoiding false calls. In a nonreferenced monitoring, that is, when MAPS-FR operates without a global riser load estimate, one cannot say whether this drift is actually a load change or only the drift behavior.

When continuously operating in a off-shore environment, MAPS-FR can generate huge amounts of data, yielding the human-based interpretation arduous and unfeasible. An automatic approach is essential as a preliminary analysis, signalizing only important events to be reviewed by experts. The method proposed in this document is the first step towards an automatic wire break detection system.

3.2. RLS Adaptive Filtering. Filters are a particular important class of linear time-invariant systems [26]. Strictly speaking, the term frequency-selective filter suggests a system that passes certain frequency components and totally rejects all others, but in a broader context any system that modifies certain frequencies relative to others is also called a filter [27]. Another meaningful definition is that filter is a device that maps its input signal to another output signal facilitating the extraction of the desired information contained in the input 


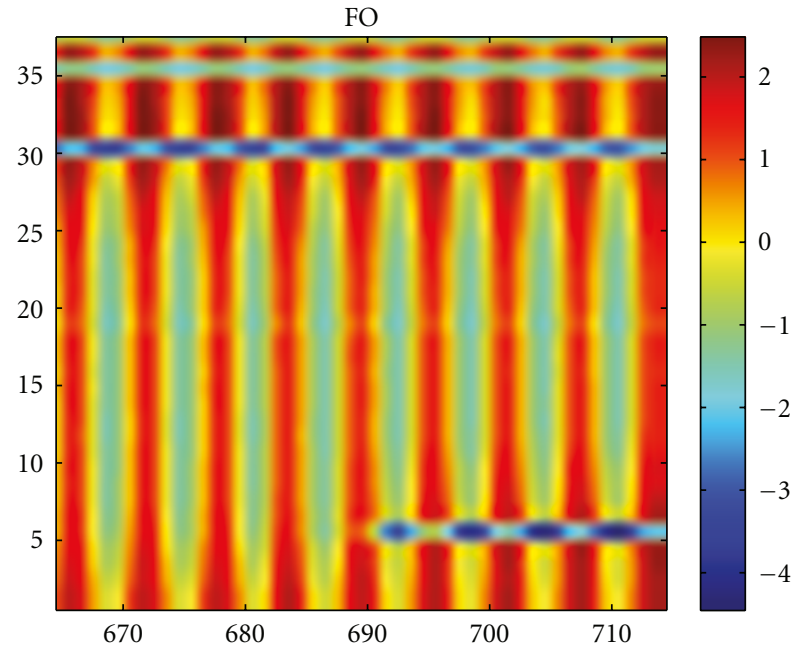

(a)

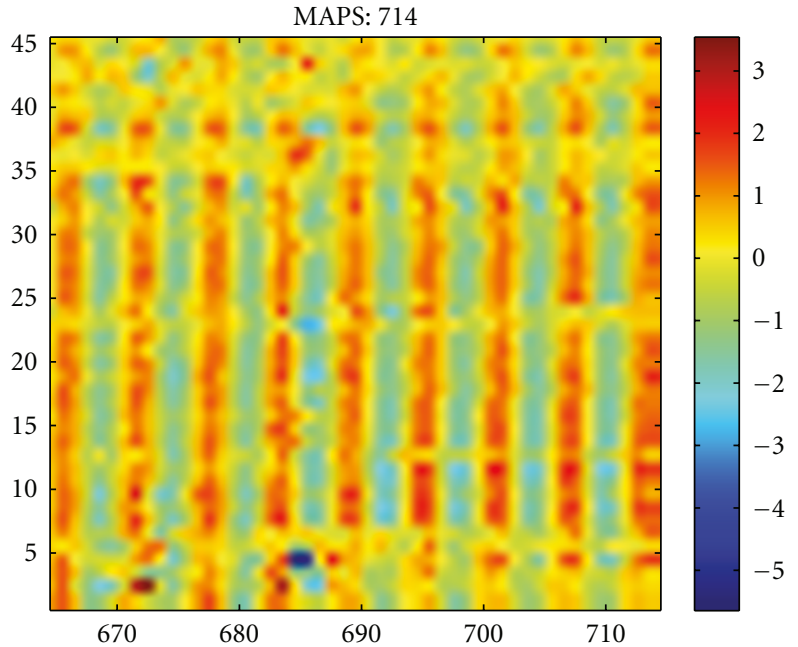

(b)

Figure 14: Wire 6 break.

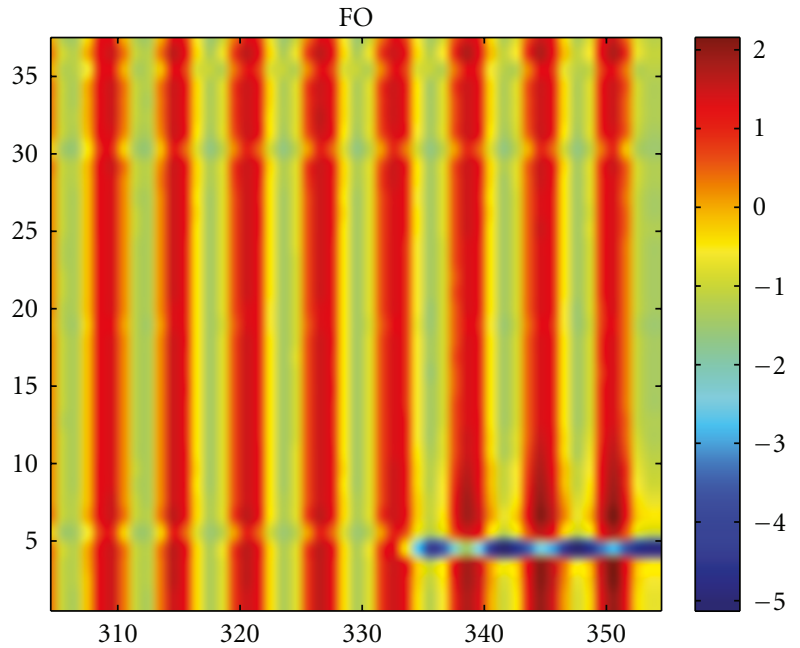

(a)

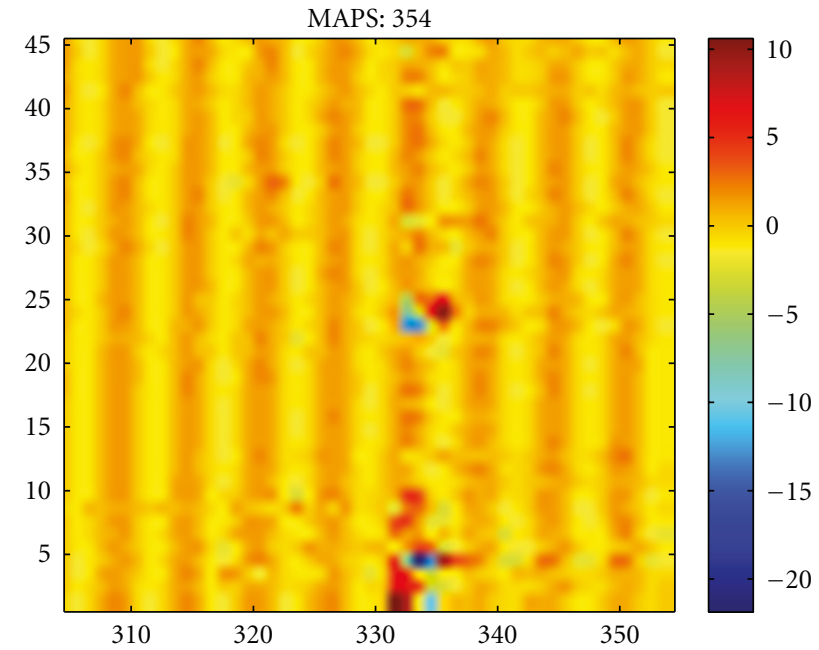

(b)

Figure 15: Wire 5 break.

signal [28]. The latter definition is particularly interesting in the context of this document.

Adaptive filters are, in turn, time-varying systems which adapt their parameters to a more suitable condition or operation point in order to achieve a specified behavior. In other words, the filter coefficients are changed so as an input signal is transformed in an output signal which is as equal as possible to a desired signal.

RLS adaptive filter class aims at the minimization of the sum of the squares of the difference between the desired signal and the filter output signal. When new samples of incoming signals are received at every iteration, the solution for the least-squares problem can be computed in recursive form resulting in the recursive least-squares (RLSs) algorithms [28].
Let $x(n)$ be the input signal, let $y(n)$ be the output signal, and let $d(n)$ be the desired signal, with $n$ representing the time. That is, $d(0)$ is the value of desired signal at time 0 . The input vector is formed by the last $N+1$ values of the input signal and is given by

$$
\mathbf{x}(n)=\left[\begin{array}{llll}
x(n) & x(n-1) & \cdots & x(n-N)
\end{array}\right]^{\mathrm{T}} .
$$

The filter, which transforms the input signal $x(n)$ into the output $y(n)$, is given by

$$
\mathbf{w}(n)=\left[\begin{array}{llll}
w_{0}(n) & w_{1}(n) & \cdots & w_{N}(n)
\end{array}\right]^{\mathrm{T}},
$$

where $N$ is the filter order. Note that due to its adaptive nature, the filter coefficients $\mathbf{w}(n)$ are time-varying, denoted 


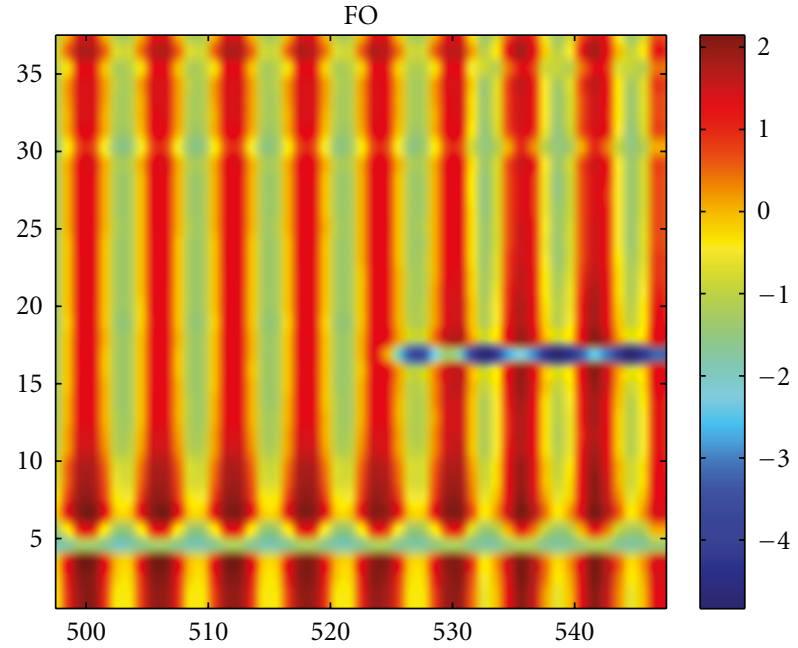

(a)

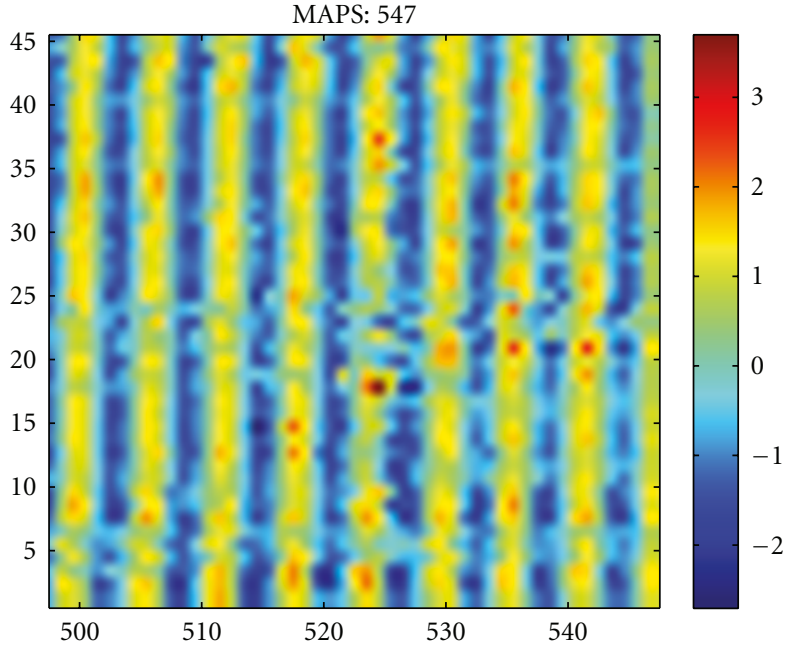

(b)

FIgURE 16: Wire 17 break.

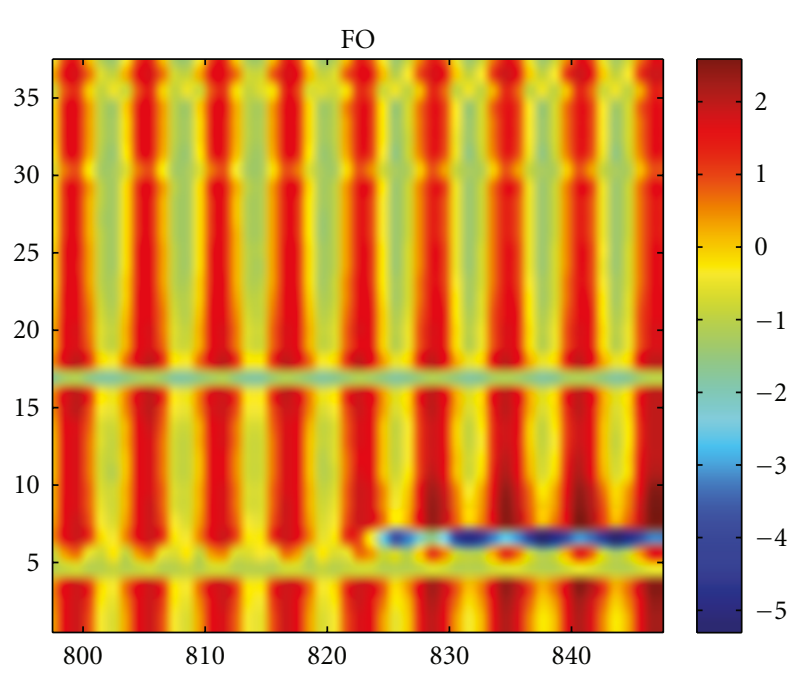

(a)

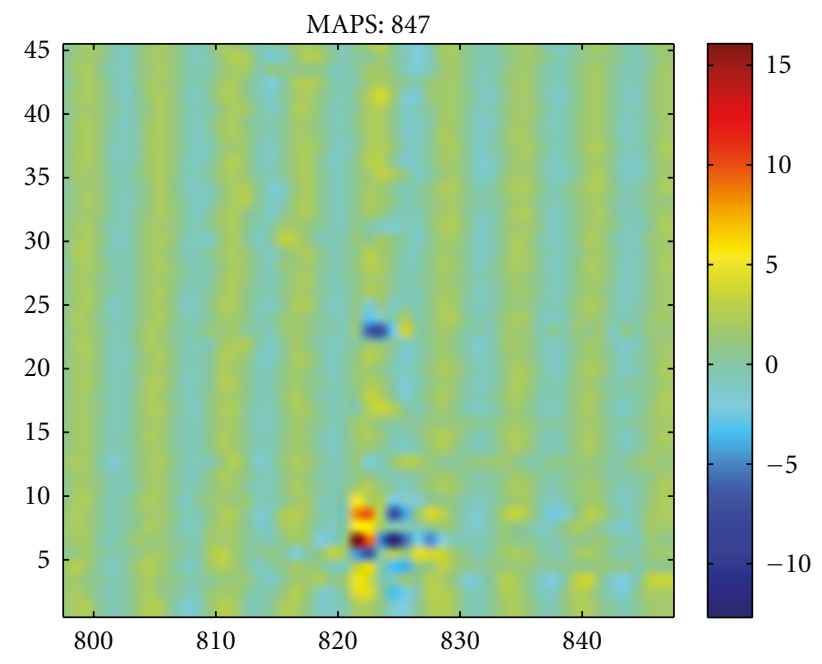

(b)

FIGURE 17: Wire 7 break.

by letter $n$. The output signal at any instant $n$ can be obtained by

$$
y(n)=\mathbf{x}^{\mathrm{T}}(n) \mathbf{w}(n-1) .
$$

The prediction error is at instant $n$ given by

$$
e(n)=d(n)-y(n) .
$$

Figure 6 depicts the general scheme of an adaptive filter. An adaptive algorithm adjusts the main filter coefficients based on some metric applied to the output error $e(n)$. In general, the adaptive algorithm will choose the main filter parameters so that the output error $e(n)$ is minimized.
The goal of RLS methods is to minimize not only the last error but also the sum of all past output errors. Thus, the objective function is given by

$$
\xi(n)=\sum_{i=0}^{n} \lambda^{n-i} \varepsilon^{2}(i)=\sum_{i=0}^{n} \lambda^{n-i}\left[d(i)-\mathbf{x}^{\mathrm{T}}(i) \mathbf{w}(n)\right]^{2}
$$

where $0 \ll \lambda<1$ is an exponential weighting factor also referred to as forgetting factor. The forgetting factor permits to put more significance and weight on recent output errors than distant past errors. The lesser the forgetting factor is, the less important are old output errors to the coefficient updating.

By differentiating $\xi(n)$ with respect to $\mathbf{w}(n)$ in (5) and performing some algebraic manipulations, the final algorithm, shown in Algorithm 1, can be deduced. 


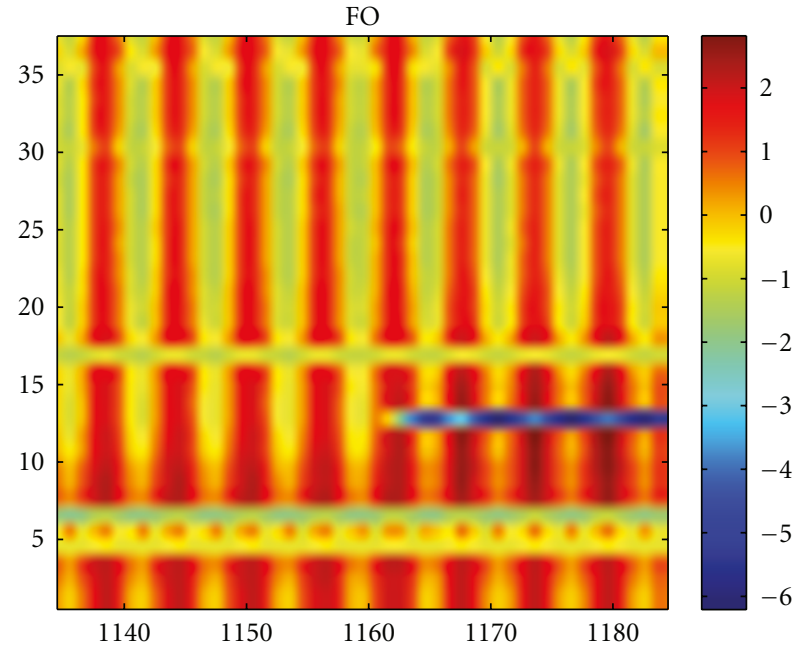

(a)

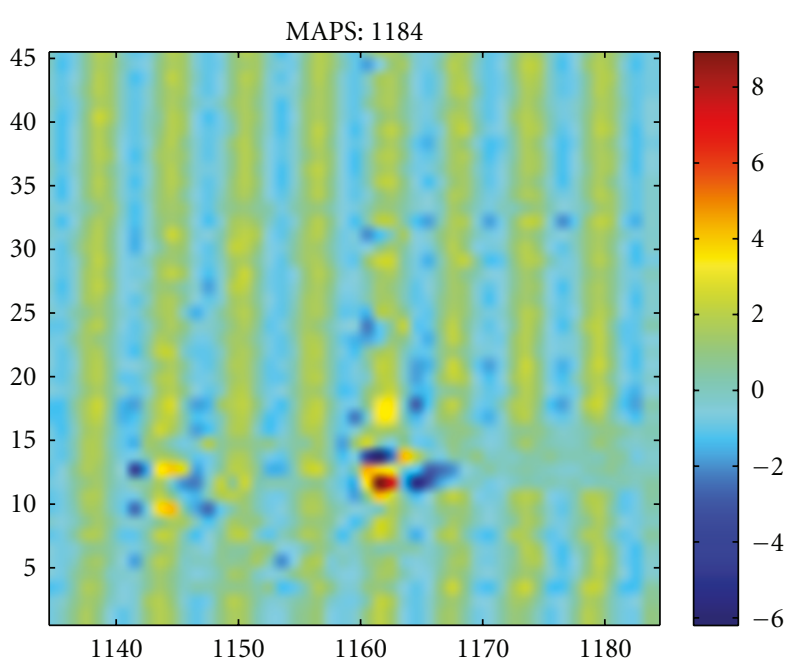

(b)

FIgURE 18: Wire 13 break.

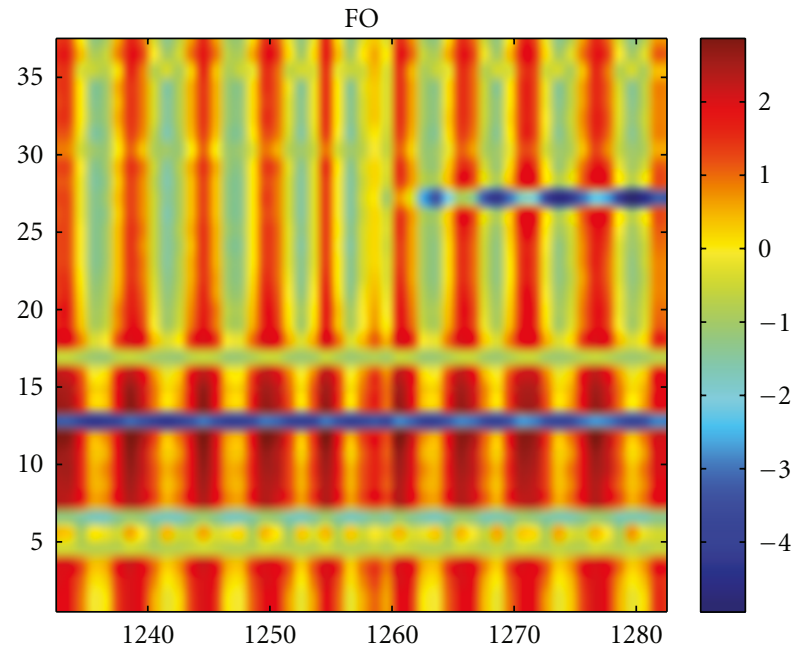

(a)

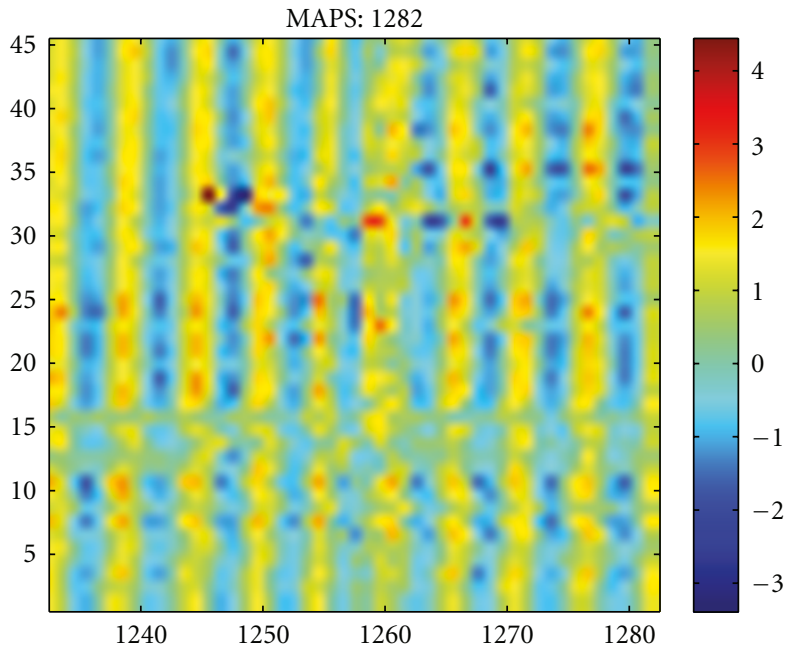

(b)

Figure 19: Wire 27 break.

The RLSs are known to pursue fast convergence and have excellent performance when working in time-varying environments. See $[28,29]$ for more information on adaptive filters and RLS algorithms.

3.3. Hybrid Approach. The current MAPS-FR tool uses 4 excitation frequencies during the acquisition yielding 4 signals per sensing coil. Each frequency shows a different sensitivity to wire stress depending on wire size, wire depth, and so forth. It will be shown that a proper combination of the 4 signals per sensing coil gives a better estimate of the stress than the one obtained by considering each signal independently.

The idea of the hybrid approach is to find a set of linear systems which map each of MAPS-FR sensing coil's signals into realistic load values. These linear systems are continuously recalculated at every iteration to compensate the slow time drift exhibited by MAPS-FR signals. Although magnetic properties of metals vary nonlinearly with mechanical load, linear systems can be used to do this mapping if some adaptation is permitted. That is, the correspondence holds (i.e., mapping becomes linear) in a small region surrounding a given operation point. Once the operation point changes, the adaptive filter recalculates its coefficients. The new filter coefficients are valid within this new region.

The hybrid approach needs an estimate of riser global load to be used as the desired signal $d(n)$. Indeed, if all wires are unbroken, the riser global load is approximately equally divided to each wire and it can be used as an estimate of stress in each wire. Since only differences between wire stresses are 
important to detect a broken wire, the riser global load is taken as desired signal for each wire (Section 3.2).

3.3.1. Problem Statement. MAPS-FR signals are arranged in a matrix form as

$$
\mathbf{X}(n)=\left[\begin{array}{cccc}
x_{1}^{(1)}(n) & x_{2}^{(1)}(n) & \cdots & x_{45}^{(1)}(n) \\
x_{1}^{(1)}(n-1) & x_{2}^{(1)}(n-1) & \cdots & x_{45}^{(1)}(n-1) \\
\vdots & \vdots & \ddots & \vdots \\
x_{1}^{(1)}(n-N) & x_{2}^{(1)}(n-N) & \cdots & x_{45}^{(1)}(n-N) \\
x_{1}^{(2)}(n) & x_{2}^{(2)}(n) & \cdots & x_{45}^{(2)}(n) \\
x_{1}^{(2)}(n-1) & x_{2}^{(2)}(n-1) & \cdots & x_{45}^{(2)}(n-1) \\
\vdots & \vdots & \ddots & \vdots \\
x_{1}^{(2)}(n-N) & x_{2}^{(2)}(n-N) & \cdots & x_{45}^{(2)}(n-N) \\
x_{1}^{(3)}(n) & x_{2}^{(3)}(n) & \cdots & x_{45}^{(3)}(n) \\
x_{1}^{(3)}(n-1) & x_{2}^{(3)}(n-1) & \cdots & x_{45}^{(3)}(n-1) \\
\vdots & \vdots & \ddots & \vdots \\
x_{1}^{(3)}(n-N) & x_{2}^{(3)}(n-N) & \cdots & x_{45}^{(3)}(n-N) \\
& & & \\
x_{1}^{(4)}(n) & x_{2}^{(4)}(n) & \cdots & x_{45}^{(4)}(n) \\
x_{1}^{(4)}(n-1) & x_{2}^{(4)}(n-1) & \cdots & x_{45}^{(4)}(n-1) \\
\vdots & \vdots & \ddots & \vdots \\
x_{1}^{(4)}(n-N) & x_{2}^{(4)}(n-N) & \cdots & x_{45}^{(4)}(n-N) \\
1 & & & 1
\end{array}\right],
$$

where $x_{q}^{(p)}(n)$ is the value of $q$ th MAPS-FR sensing coil at frequency $p$ at instant $n$. The matrix $\mathbf{X}(n)$ is of size $M \times K$, where $M=4 N+1$ are the $N$ past values of MAPS-FR signal for each of 4 frequencies, plus a constant for bias correction, and $K=45$ are the 45 sensing coils.

The filter coefficients are given by

$$
\mathbf{W}(n)=\left[\begin{array}{cccc}
w_{1,1}(n) & w_{1,2}(n) & \cdots & w_{1,45}(n) \\
w_{2,1}(n) & w_{2,2}(n) & \cdots & w_{2,45}(n) \\
\vdots & \vdots & \ddots & \vdots \\
w_{M, 1}(n) & w_{M, 2}(n) & \cdots & w_{M, 45}(n)
\end{array}\right] .
$$

A wire's stress estimate is given by

$$
y_{k}(n)=\mathbf{x}_{k}^{\mathrm{T}}(n) \mathbf{w}_{k}(n-1)
$$

where $y_{k}(n)$ is the estimate of stress in $k$ th wire at instant $n$, $\mathbf{x}_{k}(n)$ is the $k$ th column of matrix $\mathbf{X}(n)$, and $\mathbf{w}_{k}(n-1)$ is the $k$ column of matrix $\mathbf{W}(n-1)$.

Arranging $y_{k}(n)$ in a vector form, one can write $\mathbf{y}(n)=$ $\left[\begin{array}{llll}y_{1}(n) & y_{2}(n) & \cdots & y_{45}(n)\end{array}\right]^{\mathrm{T}}$. As the only reference available for the riser load is $d(n)$, it can be written as a vector $d(n)=$ $\left[\begin{array}{llll}d(n) & d(n) & \cdots & d(n)\end{array}\right]^{\mathrm{T}}=d(n)\left[\begin{array}{llll}1 & 1 & \cdots & 1\end{array}\right]^{\mathrm{T}}$.

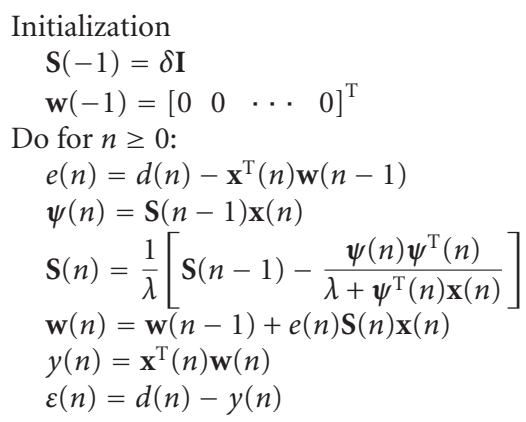

Algorithm 1: Complete RLS algorithm.

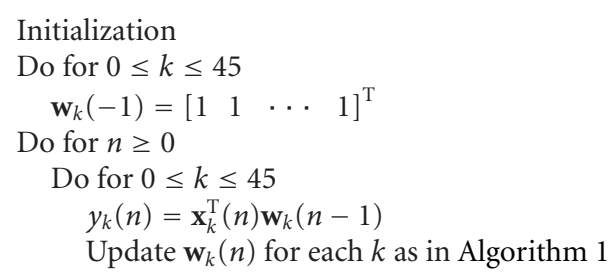

\begin{tabular}{|c|c|}
\hline Variable & Meaning \\
\hline $\begin{array}{l}\mathbf{d}(n)= \\
{\left[\begin{array}{llll}d(n) & d(n) & \cdots & d(n)\end{array}\right]^{\mathrm{T}}}\end{array}$ & $\begin{array}{l}\text { Desired signal vector: global riser } \\
\text { load estimate obtained from } \\
\text { optical strain gages. }\end{array}$ \\
\hline $\mathbf{X}(n)=\left[\begin{array}{lll}\mathbf{x}_{1}(n) & \cdots & \mathbf{x}_{45}(n)\end{array}\right]$ & $\begin{array}{l}\text { MAPS-FR signals matrix } \\
\text { organized as in }(6) \text {. }\end{array}$ \\
\hline $\begin{array}{l}\mathbf{y}(n)= \\
{\left[\begin{array}{llll}y_{1}(n) & y_{2}(n) & \cdots & y_{45}(n)\end{array}\right]^{\mathrm{T}}}\end{array}$ & $\begin{array}{l}\text { Output vector which will be } \\
\text { plotted for wire break detection. }\end{array}$ \\
\hline $\mathbf{W}(n)=\left[\begin{array}{lll}\mathbf{w}_{1}(n) & \cdots & \mathbf{w}_{45}(n)\end{array}\right]$ & $\begin{array}{l}\text { Adaptive filter matrix coefficients } \\
\text { as in ( } 7) \text { that are updated at every } \\
\text { iteration. }\end{array}$ \\
\hline
\end{tabular}

Algorithm 2: Complete Hybrid algorithm.

TABLE 4: Hybrid algorithm variables. as

The estimate error can, thus, be written in vector shape

$$
\mathbf{e}(n)=\mathbf{y}(n)-\mathbf{d}(n)
$$

Figure 7 shows the block diagram of the hybrid adaptive filter. A summary of variables is given in Table 4 and the complete algorithm is shown in Algorithm 2.

Notice that $y_{k}(n)$ is calculated with the filter coefficients $\mathbf{w}_{k}(n-1)$ obtained in the previously iteration. Consequently if a wire break occurs between time $n-1$ and $n$ at, say, wire $k=k_{0}$, the signal $y_{k_{0}}(n)$ tends to abruptly diverges from other $y_{k}(n)$ 's at instant $n$, indicating the rupture. As time passes, $\mathbf{w}_{k_{0}}(n)$ are recalculated for the new condition and the divergence between $k_{0}$ and other $k$ 's vanishes. 
The vanishing behavior is explained next: suppose that there are as many sensing coils as wires in the external armor layer. Even if each sensing coil is located exactly above each wire, respectively, due to the gap between sensing coil and wire (i.e., external polymer layer thickness), magnetic field from adjacent wires leaks laterally and affects the measurements of each other. Therefore, there exists some portion of magnetic field surrounding a broken wire that contains signals from unbroken wires. The adaptive filter parameters $\mathbf{w}_{k_{0}}(n)$ are recalculated based on this portion of signal which is coherent to the loading $d(n)$. Although this seems to be a problem, detectability at exact instant of rupture is unaffected, as will be shown in Section 4.

The units of stress and magnetic fields are irrelevant in this context. The whole system works by comparison; that is, the goal is to determine whether there is an inactive wire among active ones. Nevertheless, it is possible to establish a calibration procedure which would give rise to consistent measurements, though it is out of the scope of this document.

\section{Results}

A trial has been carried out to evaluate the performance of the proposed method. The trial took place at the riser fatigue test rig of Physical Metallurgy Laboratory (LAMEF) in Porto Alegre, Brazil. The facility allows the application of static and dynamic tensile loads exceeding 220 tons. The test sample was a section of $6^{\prime \prime}$ nominal bore new flexible production riser, rated for $3000 \mathrm{psi}$ of approximately $5 \mathrm{~m}$ length. One end of the riser was fixed and subjected to axial load (nominally connector A), whereas the other was free to rotate during loading (nominally connector B). The loading was cyclic and sinusoidal, from 160 to 220 ton and at a frequency of $0.0167 \mathrm{~Hz}$.

In the tests, the riser loadings were chosen to simulate as accurately as possible the field conditions, namely, approximately $30 \%$ to $50 \%$ of yield point. However, other field conditions such as internal pressure, arbitrary load instead of cycling load, and riser orientation (vertical instead of horizontal) were not considered. The influence of these circumstances on the results is intended to be studied in future tests.

Two windows were opened on the external sheath to access the wires. The first window was near to connector B and had a circumferential shape, giving access to all wires. This window (right side of Figure 9) was used to cut the wires during loading, simulating a real rupture. The second window was close to connector A and was used to instrument all wires with optical strain gages. The signals from these strain gages were used as references (i.e., real stress of wires). The global riser load needed for the hybrid processing was estimated averaging all strain gages signals.

The MAPS-FR was installed in the middle of the sample. This configuration was chosen to ensure that the strain gages measured similar tension values to those sensed by the MAPS-FR.
TABLE 5: Comparison between pure MAPS-FR signals and proposed method's signal and load signal.

\begin{tabular}{lc}
\hline Signal & MSE \\
\hline MAPS-FR frequency 1 & 1.1164 \\
MAPS-FR frequency 2 & 0.9781 \\
MAPS-FR frequency 3 & 0.7956 \\
MAPS-FR frequency 4 & 0.5291 \\
Proposed method & 0.2676 \\
\hline
\end{tabular}

Table 6: Trial details.

\begin{tabular}{|c|c|}
\hline Laboratory & Laboratory LAMEF at UFRGS University \\
\hline Local & Porto Alegre-RS-Brazil \\
\hline Date & $2009 / 06 / 24$ and 25 \\
\hline Sample & 5 meters long $6^{\prime \prime}$ riser sample \\
\hline Total external diameter & $250.7 \mathrm{~mm}$ \\
\hline $\begin{array}{l}\text { External sheath } \\
\text { thickness }\end{array}$ & $7 \mathrm{~mm}$ \\
\hline $\begin{array}{l}\text { Number of external } \\
\text { sheaths }\end{array}$ & 2 \\
\hline $\begin{array}{l}\text { MAPS-FR mounted } \\
\text { diameter }\end{array}$ & (1 sheath removed) $236.7 \mathrm{~mm}$ \\
\hline External armor layer & 37 flat wires: $15 \mathrm{~mm} \times 5 \mathrm{~mm}$ at 30 degrees \\
\hline $\begin{array}{l}\text { Reference } \\
\text { instrumentation }\end{array}$ & Optical strain gages on every wire \\
\hline $\begin{array}{l}\text { Global riser load } \\
\text { estimate } d(n)\end{array}$ & Average of optical strain gages \\
\hline Loading & $\begin{array}{l}\text { Sinusoidal, } 160 \text { to } 220 \text { ton, frequency } \\
0.0167 \mathrm{~Hz}\end{array}$ \\
\hline $\begin{array}{l}\text { Magnetic stress } \\
\text { measuring tool }\end{array}$ & MAPS-FR \\
\hline $\begin{array}{l}\text { Signal processing } \\
\text { algorithm }\end{array}$ & Hybrid MAPS-FR/Optical strain gage \\
\hline
\end{tabular}

Figure 8 shows a comparison between pure MAPS-FR signals and the signal obtained by the proposed method. Pure MAPS-FR signals do not represent the load well. However, when properly combined, it is possible to obtain a signal which is similar to the load that the riser is subjected to.

Table 5 summarizes the mean-square error between pure MAPS-FR signals and the loading. The phase difference between the signals was corrected previously to the error computation. The proposed method's signal is the one that best represents the riser load.

Figure 9 illustrates the setup and Table 6 summarizes the trial resources and details.

The main events of the trial are listed in Table 7. As already mentioned, the wire breaks were produced cutting them at the first window, close to connector B. In all events, the optical strain gages almost instantaneously detected the respective wire rupture. In some cases, the hybrid algorithm indicated the rupture seconds before optical strain gages.

Figure 10 illustrates a series of cyclic loads. Each of the following figures is composed of two graphs: the optical strain gages' signals are shown on the left, and processed MAPS-FR signals are shown on the right. The abscissae 
TABLE 7: Important events.

\begin{tabular}{lccc}
\hline Date & Time & Time stamp & Event \\
\hline \multirow{2}{*}{$2009 / 06 / 24$} & 15 h 15 & 250 & Wire 37 break \\
& 16 h 30 & 439 & Wire 35 break \\
& 17 h 12 & 589 & Wire 30 break \\
& 17 h 38 & 690 & Wire 6 break \\
\hline \multirow{2}{*}{$2009 / 06 / 25$} & 13 h 34 & 330 & Wire 5 break \\
& 14 h 36 & 523 & Wire 17 break \\
& 16 h 14 & 823 & Wire 7 break \\
& 17 h 52 & 1160 & Wire 13 break \\
& 18 h 21 & 1258 & Wire 27 break \\
\hline
\end{tabular}

represent time stamp, whereas the ordinates represent wire number (a) or sensing coil number (b). Given a wire number and a time instant, the correspondent color indicates the stress level. In both graphs, there is a scale bar on the right which relates the color to a statistically normalized stress parameter.

Figures 11 to 19 show the rupture moment of several wires. It is clear on the left graphs which wire was cut. The color difference indicates that the damaged wire diverges from the unbroken ones; that is, cut wires tend to loosen. Although there is some noise on the right graphs, it is possible to determine the rupture instant in most cases. Moreover, the scale range of processed MAPS-FR signals remains between -3 and +3 during normal operation. When a rupture occurs, its limits reach from \pm 3.5 to \pm 20 . This could be used as a criterion for automatic detection.

\section{Conclusion}

Flexible risers are multilayered pipes used in oil and gas industry. Their complex geometry imposes difficulties (i.e., unknown wire arrangement) when assessing stress in internal layers through the outer polymeric sheath. Unknown wire arrangement and in-service wire reaccommodation introduce uncertainties while measuring internal stress.

This article proposes a new estimation method of internal stress distribution by combining electromagnetic measurements with optical strain gage data. Electromagnetic measurements are converted into load values through adaptive filters. Optical strain gage signal is used as an estimate of riser global load. This signal is used as desired signal in the adaptive context. In other words, it is assumed that in normal conditions riser global load is equally divided between wires.

A set of adaptive linear filters is calculated so as each of the MAPS-FR signals is converted into load. The filters' inputs are electromagnetic signals, and the filters' outputs are load estimates of correspondent wires. When a wire rupture occurs, the filter produces indications that the load changed, and the break can be detected.

The main advantage of the proposed technique is that it does not need the external sheath to be removed; that is, it is a nonintrusive technique. Yet, it can detect singlewire ruptures. The riser global load estimate, required by the proposed method, can be obtained through strain gages installed on the external sheath or by the FBG strain gage collar mentioned in Section 2.2 and described in [21]. The collar can detect and estimate the riser global load in a nonintrusive manner.

The presented results showed that the proposed technique produces graphical representations on which visual detection of wire breaks can be effectively performed in most cases. The proposed method can be straightforwardly extended to automatically detect wire ruptures. A simple fixed threshold or statistically variable threshold could be employed for this purpose.

\section{Acknowledgments}

The authors would like to acknowledge Petrobras Research and Development Center (CENPES) for its incentive and financial support. The authors would like to acknowledge also MAPS Technology and MAPS team for the partnership, collaboration, corrections, and experience exchange during the production of this work.

\section{References}

[1] H. Corrignan, R. T. Ramos, R. J. Smith, S. Kimminau, and L. El Hares, "New monitoring technology for detection of flexible armor wire failure," in Proceedings of the Offshore Technology Conference (OTC '09), 2009.

[2] M. G. Marinho, C. S. Camerini, S. R. Morikawa, D. R. Pipa, G. P. Pires, and J. M. Santos, "New techniques for integrity management of flexible riser end-fitting connection," in Proceedings of the 27th International Conference on Offshore Mechanics and Arctic Engineering, Estoril, Portugal, June 2008.

[3] J. C. McCarthy and D. J. Buttle, "Non-invasive magnetic inspection of flexible riser," in Proceedings of the Offshore Technology Conference (OTC '09), Houston, Tex, USA, May 2009.

[4] Technip, "Flexible pipe brochure," 2008, http://www.technip .com/pdf/Flexible_Pipe.pdf.

[5] Health and S. Executive, "Guidelines for integrity monitoring of unbonded flexible pipe," Tech. Rep., Health and Safety Executive, 1998.

[6] M. G. Marinho, J. M. dos Santos, and R. D. O. Carneval, "Integrity assessment and repair techniques of flexible risers," in Proceedings of the 25th International Conference on Offshore Mechanics and Arctic Engineering (OMAE '06), Hamburg, Germany, June 2006.

[7] A. P. Institute, API RP 17B-Recommended Practice for Flexible Pipe, API Publishing Services, Washington, DC, USA, 2002.

[8] A. Berg and N. J. Rishøj-Nielsen, "Integrity monitoring of flexible risers by optical fibres," in Proceedings of the 21st International Conference on Offshore Mechanics and Arctic Engineering (OMAE'02), vol. 3, pp. 47-52, 2002.

[9] L. A. Mesquita, J. M. Santos, P. Loureiro, and A. L. Carvalho, "Monitoramento das válvulas de despressurização de gás percolado no espaço anular de risers de produção e exportação de óleo e gás," in Proceedings of the Rio Pipeline Conference and Exposition, 2005.

[10] A. Felix-Henry and P. Lembeye, "Flexible pipes in-service monitoring," in Proceedings of the 23rd International Conference on Offshore Mechanics and Arctic Engineering (OMAE '04), vol. 3, pp. 149-154, 2004. 
[11] J. Marsh, P. Duncan, and I. MacLeod, "Offshore pipeline and riser integrity - the big issues," in Proceedings of the Offshore Technology Conference (OTC '09), 2009.

[12] C. Saunders and T. O'Sullivan, "Integrity management and life extension of flexible pipe," in Proceedings of the Offshore Technology Conference (OTC '07), 2007.

[13] J. W. Picksley, K. Kavanagh, S. Garnham, and D. Turner, "Managing the integrity of flexible pipe field systems: industry guidelines and their application," in Proceedings of the Annual Offshore Technology Conference, pp. 609-618, 2002.

[14] J. Picksley, "State of the art flexible riser integrity issues: study report," Tech. Rep., MCS International, 2001.

[15] N. Weppenaar, A. Kosterev, L. Dong, D. Tomazy, and F. Tittel, "Fiberoptic gas monitoring of flexible risers," in Proceedings of the Offshore Technology Conference (OTC '09), 2009.

[16] R. Roberts, S. Garnham, and B. D'All, "Fatigue monitoring of flexible risers using novel shape-sensing technology," in Proceedings of the Offshore Technology Conference (OTC '07), 2007.

[17] R. Thethi, H. Howells, S. Natarajan, and C. Bridge, "A fatigue monitoring strategy and implementation on a deepwater top tensioned riser," in Proceedings of the Offshore Technology Conference (OTC '05), 2005.

[18] E. Binet, P. Tuset, and S. Mjøen, "Monitoring of offshore pipes," in Proceedings of the Offshore Technology Conference (OTC'03), 2003.

[19] M. G. Marinho, C. S. Camerini, J. M. Santos, and G. P. Pires, "Surface monitoring techniques for a continuous flexible riser integrity assessment," in Proceedings of the Offshore Technology Conference (OTC '07), Houston, Tex, USA, 2007.

[20] S. D. Soares, C. S. Camerini, and J. M. C. de Santos, "Development of flexible risers monitoring methodology using acoustic emission technology," in Proceedings of the Offshore Technology Conference (OTC '09), 2009.

[21] S. R. K. Morikawa, C. S. Camerini, D. R. Pipa et al., "Monitoring of flexible oil lines using FBG sensors," in Proceedings of the 19th International Conference on Optical Fibre Sensors, vol. 7004 of Proceedings of SPIE, pp. 70 046F1-70 046F-4, April 2008.

[22] M. Andersen, A. Berg, and S. Saevik, "Development of an optical monitoring system for flexible risers," in Proceedings of the Offshore Technology Conference (OTC '01), 2001.

[23] http://www.maps-technology.com/.

[24] B. DJ, "Emerging technologies for in-situ stress surveys," in Proceedings of the 6th International Conference on Residual Stresses (ICRS '00), 2000.

[25] B. DJ and S. CB, "Residual stresses: measurement using magnetoelastic effects," in The Encyclopaedia of Materials: Science and Technology, 2001.

[26] P. S. R. Diniz, E. A. B. da Silva, and S. L. Netto, Digital Signal Processing: System Analysis and Design, Cambridge University Press, Cambridge, UK, 2002.

[27] J. B. A. V. Oppenheim and R. W. Schafer, Discrete-Time Signal Processing, Prentice-Hall, Upper Saddle River, NJ, USA, 2nd edition, 1997.

[28] P. S. R. Diniz, Adaptive Filtering: Algorithms and Practical Implementations, Springer, Boston, Mass, USA, 3rd edition, 2008.

[29] S. Haykin, Adaptive Fiter Theory, Prentice-Hall, Upper Saddle River, NJ, USA, 3rd edition, 1996. 